\title{
EL ANÁLISIS DEL SECTOR TURÍSTICO EN BÉJAR COMO CASO DE ESTUDIO DE LAS NUEVAS POLÍ- TICAS URBANAS EN LAS PEQUEÑAS CIUDADES
}

\author{
Michael BROSSMANN \\ Westfälische Wilhelms-Universität Münster.
}

Recibido: 11/09/2009

Aceptado: 11/04/2010

RESUMEN: Como respuesta al declive prolongado de la industria local, la ciudad de Béjar está intentando diversificar y consolidar su economía urbana mediante la aplicación de diversas medidas que, en su conjunto, se encuadran dentro de lo que se conoce como nuevas políticas urbanas. En este sentido, el Ayuntamiento ha asignado al turismo un papel central en la búsqueda de alternativas al sector secundario y en la consiguiente revitalización del tejido socioeconómico. El artículo lleva a cabo un análisis detallado de este sector como caso de estudio de dichas políticas en las pequeñas ciudades industriales y lo compara con el papel que le asigna el marco teórico correspondiente. Así mismo, derivamos de este análisis algunas conclusiones sobre la trayectoria futura del sector turístico y sus posibilidades para sostener la economía local bejarana en el futuro.

PALABRAS CLAVE: Nuevas políticas urbanas, pequeñas ciudades industriales, Béjar, turismo.

AN ANALYSIS OF THE TOURISM SECTOR IN BEJAR: A CASE STUDY OF NEW URBAN POLICIES IN SMALL INDUSTRIAL TOWNS

ABSTRACT: As a response to the continual decline of the local industry, the city of Béjar is trying to diversify and consolidate its urban economy. It is doing this by means of various measures, which as a whole belong to what is known as New urban politics. In this sense, the local authorities have assigned a central role to tourism in the search for alternatives to the secondary sector and aim for it to be a tool in the subsequent revitalization of the socio-economic situation. This paper carries out a detailed analysis of the tourism sector as a case study of the aforementioned New urban politics as applied to small industrial cities and compares it with its position in the corresponding theoretical concept. Furthermore, from this analysis the author will derive conclusions about the future trajectory of the tourism sector and its ability to sustain Béjar's local economy in the future.

KEY WORDS: New urban politics, small industrial cities, Béjar, tourism.

ANALYSE DU SECTEUR TOURISTIQUE DE BÉJAR COMME CAS D'ÉTUDE DES
NOUVELLES POLITIQUES URBAINES DANS LES PETITES VILLES
INDUSTRIELLES
RÉSUMÉ: Comme réponse au déclin prolongé de l'industrie locale, la ville de Béjar essaie
diversifier et consolider son économie urbaine à travers la mise en place de différentes me-
es qui, dans leur ensemble, font parties de ce que l'on appelle les nouvelles politiques ur- 
baines. Dans ce sens, la municipalité a assigné au tourisme un rôle central dans la recherche d'alternatives pour le secteur secondaire et la revitalisation du secteur économique. Cet article est une analyse détaillée qui étudie à travers le cas de Béjar, le rôle du tourisme dans les nouvelles politiques urbaines des petites villes industrielles. Ce rôle est comparé aux positions théoriques habituellement assignées au secteur touristique dans ces politiques. Nous tirerons de cette analyse quelques conclusions à propos du développement touristique à venir et de ses capacités à subvenir au maintient la future économie locale.

MOTS-CLÉS: Nouvelles politiques urbaines, petites villes industrielles, Béjar, tourisme.

O ANÁLISE DO SETOR TURÍSTICO EM BÉJAR COMO CASO A SER ESTUDADO DAS NOVAS POLÍTICAS URBANAS NAS PEQUENAS CIDADES INDUSTRIAIS

RESUMO: A cidade de Béjar tenta, como resposta ao declive prolongado da indústria local, diversificar e consolidar a sua economia urbana mediante a aplicação de diversas medidas que em seu conjunto se enquadram dentro do que conhecemos como novas políticas urbanas. Neste sentido, a prefeitura municipal definiu o turismo como uma actividade central para promover alternativas ao sector secundário e para consequentemente conseguir a regionalização do tecido socioeconómico. Uma análise detalhada deste sector é feita neste artigo, tendo como estudo de caso as ditas políticas nas pequenas cidades industriais, comparadas com o papel atribuído ao conceito teórico correspondente. Apresentamos desta forma a análise tirando algumas conclusões sobre a trajectória futura do sector turístico e suas possibilidades para a sustentabilidade da economia local bejarana no futuro.

PALAVRAS-CHAVES: Novas políticas urbanas, pequenas cidades industriais, Béjar, turismo.

\section{INTRODUCCIÓN}

Durante un amplio período de tiempo la industria determinaba la trayectoria socioeconómica de muchas ciudades españolas. Sobre todo, en algunas poblaciones de tamaño reducido llegaba a definir la identidad y la imagen de la ciudad, bien por la presencia de una gran compañía (ciudad-empresa) o bien por una red de pequeñas firmas integradas en sistemas productivos locales (SÁNCHEZ HERNÁNDEZ et al., 2006, 466). El sector turismo, en cambio, sólo tenía un papel muy inferior en estas economías locales. En la actualidad, sin embargo, cada vez más dichas pequeñas ciudades industriales desarrollan medidas para reforzar la actividad turística en sus políticas urbanas. Estas medidas forman parte de un cambio de estrategia generalizado, desde un enfoque dirigido exclusivamente a las actividades industriales tradicionales que, casi en su totalidad, entraron en crisis en la segunda mitad del siglo XX, hacia otro que busca una base económica más diversificada. El conjunto de todas estas acciones es conocido como las nuevas politicas urbanas.

En este trabajo analizamos la situación del sector turístico en la ciudad de Béjar como un caso de estudio de dichas políticas en las pequeñas ciudades industriales españolas. El objetivo de nuestro análisis es responder, sobre todo, a dos preguntas: 1) ¿Coinciden la actividad turística y las políticas correspondientes con el papel que tienen en el marco teórico de las nuevas políticas urbanas? 
y 2) ¿Qué posición tendrá el sector turístico en la economía bejarana del futuro? Antes de entrar en el análisis, con el fin de ubicar y contextualizar la ciudad de Béjar y para entender su identidad de pequeña ciudad industrial, resumimos, de una manera introductoria y breve, sus características más importantes, así como la trayectoria industrial de Béjar en el último siglo. Igualmente damos una visión conjunta del concepto de las nuevas políticas urbanas.

\section{La ciudad de Béjar}

Béjar se encuentra en el borde meridional de la Comunidad Autónoma de Castilla y León. Pertenece a la provincia de Salamanca y está ubicada a unos 73 kilómetros al sur de la capital provincial siguiendo la N-630, la vieja Ruta de la Plata. Situada en el Sistema Central, la ciudad se caracteriza por un relieve montañoso y tiene una altitud de 959 metros sobre el nivel del mar (Cf. FIGURA 1). Según el Padrón Municipal del 1 de enero de 2008, Béjar cuenta con 15.510 habitantes (INSTITUTO NACIONAL DE ESTADÍSTICA -INE- 2008). A pesar de este tamaño reducido, constituye el centro de la comarca debido a la carencia de otras aglomeraciones urbanas considerables, un hecho que muestra la ubicación relativamente remota y aislada de la ciudad.

Figura 1. Localización de la ciudad de Béjar y principales vías de comunicación
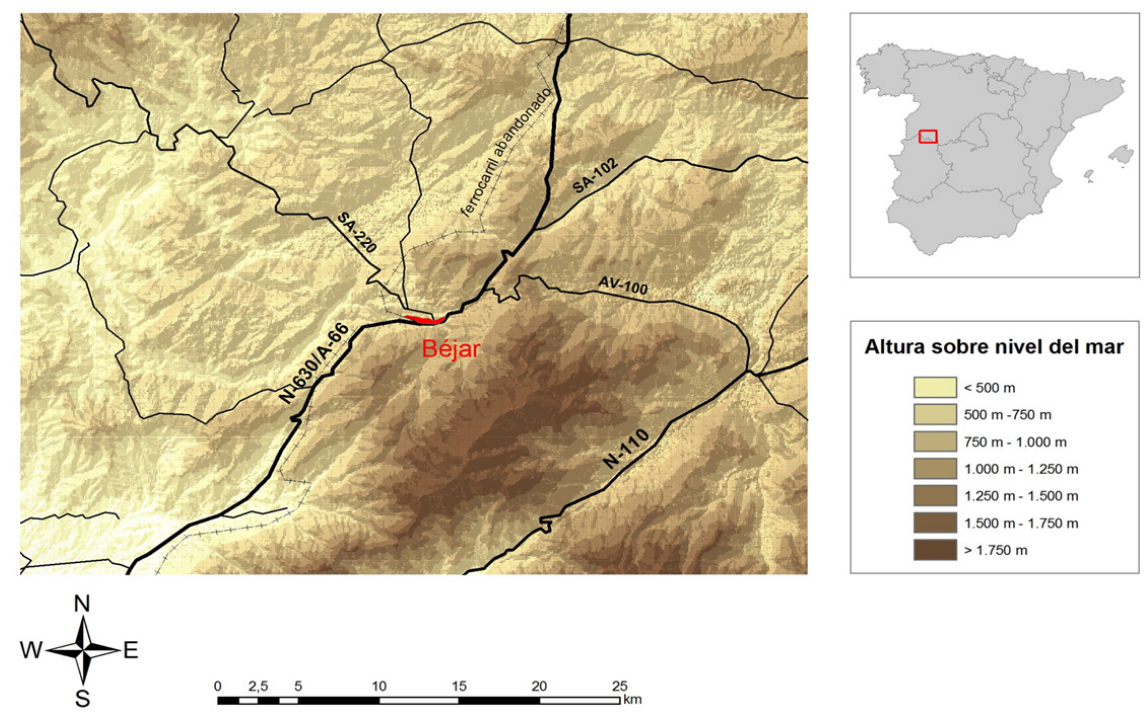

FUENTE: elaboración propia a partir de datos del Instituto Geográfico Nacional

La trayectoria de Béjar está vinculada estrechamente con la industria textil. La tradición lanera, que se remonta, al menos, hasta finales del siglo XV, se des- 
arrolló gracias a la trashumancia y la calidad de las aguas del río Cuerpo de Hombre, que era necesaria para los procesos del lavado y los tintes. El período más exitoso de la industria textil bejarana empezó tras la Guerra Civil, cuando se convirtió en uno de los proveedores principales de paños de lana que se utilizaban, en su mayor parte, para la confección de uniformes militares o de otros cuerpos de funcionarios públicos. En 1958, 3.243 personas, casi la mitad de la población activa, trabajaban en 153 unidades textiles, lo que supone el punto álgido en cuanto al empleo y los establecimientos. Atraído por la floreciente industria textil, en este período, Béjar alcanzó un saldo migratorio positivo y continuó su crecimiento hasta el año 1970, cuando llegó al valor máximo de 17.576 habitantes (SÁNCHEZ HERNÁNDEZ, 2002, 156).

En los años 1960 se llevó a cabo una modernización y tecnificación del sistema textil, que causó una concentración empresarial y una caída del empleo. Esto supone el principio de una crisis crónica del sector textil, que se extiende hasta la actualidad. Durante los años 1970, el sector textil bejarano, al igual que diversas industrias en toda Europa, sufrió el cierre de muchas fábricas y grandes recortes en la plantilla. Tras una ligera recuperación en los años 1980, impulsada por el ingreso en la Comunidad Europea, entró en una nueva crisis a partir de los años 1990 (SÁNCHEZ HERNÁNDEZ, 2002, 156). Hasta el año 2008, el número de unidades productivas se ha reducido hasta 44, que emplean un total de 360 trabajadores (AGRUPACIÓN DE FABRICANTES DE BÉJAR, 2009; CAMERDATA, S. A., 2009).

Debido al peso considerable de la industria en Béjar y la monoespecialización en el sector textil, la crisis del mismo es, de hecho, una crisis de la propia ciudad, tanto en términos socioeconómicos como en lo que respecta a la identidad y la cultura local, que está íntimamente relacionada con la tradición lanera. Como en otras pequeñas ciudades industriales, el Ayuntamiento bejarano intentó frenar el deterioro de la economía local con una reindustrialización, en concreto, con la reactivación del sector principal en declive. Este intento, sin embargo, fracasó y, además, no surgieron alternativas industriales ni un sector servicios que podía sostener la economía local (SÁNCHEZ HERNÁNDEZ, 2002, 159). Ante el deterioro socioeconómico que acarreó el prolongado período de crisis, el Ayuntamiento comenzó a cambiar paulatinamente su estrategia y aplicó medidas más diversificadas tanto en lo referente a la industria como a los servicios. En esta nueva estrategia, el fomento del sector turismo ocupa una posición central (AGENCIA DE DESARROLLO, 2009a).

\section{El concepto de las nuevas políticas urbanas}

Ni el declive de las industrias tradicionales a lo largo del siglo XX, ni los intentos de renovación y diversificación de la base económica local son fenóme- 
nos propiamente españoles. Al contrario, muchas ciudades europeas y norteamericanas siguieron una trayectoria similar y en este proceso, especialmente a partir de los años 1980, varias de ellas intentaron aprovecharse del turismo como nueva fuente de ingreso e implementaron medidas para fomentar este sector (SÁNCHEZ HERNÁNDEZ, 2002; LAW, 1992; LAW, 2002).

A partir de los años 1990 se desarrollaron diversas investigaciones sobre estas políticas y el "urban tourism" (LAW, 1992); es decir, el turismo hacia las ciudades industriales o, de modo más general, hacia las ciudades tradicionalmente no turísticas. Existe una gran variedad de investigaciones y casos de estudio sobre diferentes ciudades, entre otros se pueden mencionar CONNELLY (2007) y LEVINE (2003) con sus estudios turísticos sobre Liverpool y Montreal. En cuanto a la base teórica, cabe destacar, sobre todo, los trabajos de LAW $(1992,1996$, 2000, 2002), que analizó el 'turismo urbano' detalladamente investigando su papel en la revitalización del tejido urbano, su organización, las estrategias de su implementación, los diferentes tipos (sobre todo el turismo cultural, de deporte, de artes, de conferencias y de eventos especiales), así como los diversos factores de atracción. Sin embargo, él basa sus investigaciones casi exclusivamente en casos de estudio norteamericanos e ingleses, además se centra en ciudades grandes, por lo cual para el caso examinado en este artículo no se pueden tomar sus estudios como referencia teórica sin generalizar en exceso; por ello recurrimos, en su lugar, al marco teórico de BENITO DEL POZO (2004). Esta autora analizó la trayectoria de la ciudad de Avilés y derivó, a partir de este análisis, un modelo interpretativo sobre la trayectoria y las políticas urbanas en las pequeñas ciudades industriales españoles tras la crisis del sector secundario.

Según BeNITO DEL POZO, las primeras respuestas de las autoridades locales fueron intentos de reindustrialización mediante la promoción de este sector y la creación de infraestructuras adecuadas. Tras el fracaso de la reindustrialización, modificaron el enfoque y se inició un proceso de terciarización de la economía local y de renovación urbanística del espacio urbano. El abanico de las medidas aplicadas se conoce como las nuevas políticas urbanas, que tienen como objetivo general el fomento de la economía y la competitividad de la ciudad tanto en lo que se refiere al tejido socioeconómico local como a la captación de recursos externos (BENITO DEL POZO, 2004; SÁNCHEZ HERNÁNDEZ ET AL., 2006).

Un elemento clave en este proceso es la revalorización del espacio urbano. Se trata de la rehabilitación de espacios industriales abandonados y zonas deterioradas y de su reutilización para actividades alternativas. En este sentido muchas de las viejas fábricas en desuso se convierten, entre otras cosas, en museos, centros culturales o salas de congresos. Así, se pretende crear una nueva centralidad del espacio urbano y generar valores que se pueden transformar en recursos económicos. Sin embargo, no se lleva a cabo la renovación urbanística con la 
desarticulación completa de la herencia industrial, sino, por el contrario, con una creciente sensibilidad y con la recuperación del patrimonio de las actividades industriales, que determinaron la trayectoria de las ciudades durante un período extenso llegando a formar parte de su identidad urbana. Dado que la imagen exterior de la mayoría de estas ciudades aún está determinada por su pasado industrial y asociada con la presencia de fábricas con impactos negativos para su entorno, dicha revalorización, así como las medidas de marketing urbano, son de una gran importancia para la atracción de turistas. Generalmente van acompañadas por una ampliación y una mejora cualitativa de la infraestructura turística que, hasta este momento, era muy escasa. El fin de estas medidas es la consolidación de un sector turístico que, en la mayoría de los casos, supone la fuente principal de recursos externos (BENITO DEL POZO, 2004; BENITO DEL PozO, 2005).

Otro elemento importante es el papel que desempeñan los agentes públicos en las nuevas políticas urbanas. Sus actividades se caracterizan por una orientación emprendedora y superan claramente las funciones tradicionales de ordenación del territorio y prestación de servicios públicos. Las autoridades locales están involucradas en los procesos económicos activamente de tal forma que asesoran a las empresas locales, facilitan ayudas públicas para la creación de nuevos negocios y actúan como gestores en algunos proyectos de dinamización empresarial (SÁNCHEZ HERNÁNDEZ et al., 2006).

Hay que destacar además que, al contrario de lo que ocurría en la fase de reindustrialización fracasada, las medidas aplicadas ya no se orientan estrictamente hacia los sectores económicos, sino que adoptan un enfoque territorial más coherente y comprensivo. Así, la visión parcial concentrada en las actividades industriales ha sido sustituida por un enfoque integral que contempla el conjunto de la ciudad con sus actividades e interrelaciones con el entorno comarcal e incluso regional (BENITO DEL POZO, 2004; SÁNCHEZ HERNÁNDEZ ET AL., 2006).

\section{LA IMPORTANCIA DEL SECTOR TURISMO EN BÉJAR.}

\section{El papel en la economía local.}

El turismo, especialmente el de montaña, tiene una cierta tradición en Béjar. Sin embargo, los turistas nunca llegaron a un número elevado y, por lo tanto, este sector contribuía muy poco al empleo y a los ingresos del municipio. En la actualidad, tras el declive continuado de la industria textil, el sector turismo está mucho más presente en las políticas económicas municipales. Lamentablemente, no hay datos disponibles a escala municipal sobre el porcentaje concreto en que contribuye al PIB o al empleo. Sin embargo, se pueden obtener algunas ob- 
servaciones considerando las evaluaciones de la Agencia de Desarrollo Local del Ayuntamiento de Béjar y la Cámara de Comercio, así como analizando los datos del comercio local relacionado con el turismo.

Dichas entidades atribuyen al turismo una importancia considerable en la economía local. De acuerdo con lo que mencionamos anteriormente, el Ayuntamiento asigna al sector turismo un papel central en sus intentos de diversificar la base económica local y encontrar nuevas fuentes de ingreso; por ello, la importancia de las actividades turísticas se ha incrementado en los últimos años. Se espera, además, que continúe incrementándose en el futuro próximo y tenga una posición central en la trayectoria económica futura de Béjar (AGENCIA DE DESARROLlo, 2009a; CÁMARA DE COMERCIO, 2009).

Estas evaluaciones coinciden parcialmente con los datos del Impuesto sobre Actividades Económicas (IAE) en lo que se refiere al sector turismo facilitados por la Cámara de Comercio para los años 1999 y 2008. El conjunto de actividades relacionadas directa e indirectamente con el turismo ha disminuido en $25 \mathrm{li}$ cencias, lo cual significa un total de 128 unidades en comparación con las 153 del año 1999. Sin embargo, este descenso radica casi completamente en la desaparición de cafés y bares, es decir, comercios que solamente tienen una vinculación secundaria con el turismo. Al contrario, considerando el número de comercios relacionados directamente con el turismo, como es el caso de las agencias de viajes, los diferentes tipos de alojamiento y los comercios turísticos especializados como la gestora de la oficina de turismo, se ha efectuado un ligero incremento llegando a un total de 19 unidades en el año 2008; además, el número de restaurantes de uno o dos tenedores se incrementó en 9 establecimientos llegando a unos 30 en la actualidad (IAE, 1999; IAE, 2008).

Se puede concluir de todo esto que en el día de hoy el turismo tiene un papel importante en las políticas urbanas de Béjar y que su peso en la economía local se ha incrementado ligeramente en cuanto a la cantidad de negocios en los últimos años. Sin embargo, puesto que no hay datos disponibles sobre el nivel de negocio de los comercios turísticos, no es posible determinar su contribución exacta a la economía local.

\section{La importancia a escala nacional.}

Si bien el turismo está en auge en la economía local bejarana y ocupa una posición central en las políticas urbanas, esto no significa necesariamente que la ciudad constituya un núcleo de fuerte atracción turística en comparación con otros municipios, como demuestra el análisis del Índice Turístico del Anuario Económico de La Caixa. Este índice se calcula en función del número de habitaciones en alojamientos turísticos, de su ocupación anual, así como de la cate- 
goría de los alojamientos y se relaciona con el total de los datos referidos a España. Las últimas informaciones al respecto son del año 2006 y las anteriores corresponden al año 2001 (LA CAIXA, 2008b).

En el caso de Béjar, el Índice Turístico se eleva a 11 en el año 2006, lo que supone la posición 539 en toda España. Dentro de la provincia de Salamanca, Béjar se encuentra en la sexta posición, superado por la ciudad de Salamanca (386), Santa Marta de Tormes (62), Ciudad Rodrigo (18), La Alberca (14) y Villamayor (12). Tomando en cuenta estas cifras se observa que el Índice Turístico de Béjar se incrementó 3 puntos entre 2001 y 2006, lo cual conllevó un aumento de 17 posiciones respecto al conjunto español; a escala provincial, sin embargo, perdió una posición a causa del fuerte incremento del índice de Villamayor (LA CAIXA, 2008a). El siguiente cuadro resume los resultados más importantes:

Cuadro 1. Índice Turístico de los principales municipios turísticos en la provincia de Salamanca

\begin{tabular}{lccc}
\hline Municipio & $I T$ & $P P$ & $P N$ \\
\hline Salamanca & $386(+19)$ & $1(=)$ & $51(\Uparrow 3)$ \\
Santa Marta & $62(+17)$ & $2(=)$ & $187(\Uparrow 21)$ \\
Ciudad Rodrigo & $18(+1)$ & $3(=)$ & $402(\Downarrow 29)$ \\
La Alberca & $14(+5)$ & $4(=)$ & $484(\Uparrow 28)$ \\
Villamayor & $12(+12)$ & $5(\Uparrow 1)$ & $533(\Uparrow 1505)$ \\
Béjar & $11(+3)$ & $6(\Downarrow 1)$ & $539(\Uparrow 17)$ \\
\hline
\end{tabular}

IT = Índice turístico 2006 (2001); PP = Posición provincial 2006 (2001) PN = Posición nacional 2006 (2001)

FUENTE: Elaboración propia a partir de LA CAIXA, 2008a

La comparación de los Índices Turísticos muestra que a escala nacional la importancia del sector turismo en Béjar es muy baja. A escala provincial tiene una posición considerable, aunque claramente inferior a la ciudad de Salamanca, que supera visiblemente los Índices Turísticos del resto de la provincia, y también muy inferior al de Santa Marta de Tormes. Hay que destacar, sin embargo, que el turismo de Santa Marta de Tormes, así como el de Villamayor, se basa casi exclusivamente en su proximidad a la ciudad de Salamanca. El incremento de sus Índices Turísticos se explica por el fuerte aumento de capacidades de alojamiento en los últimos años; los índices de Ciudad Rodrigo y La Alberca, no obstante, se basan en sus propios potenciales turísticos.

De todo ello, se pueden deducir cuatro conclusiones principales. Primera, el incremento del Índice Turístico documenta las evaluaciones realizadas por parte de la Agencia de Desarrollo Local y la Cámara de Comercio, así como también 
lo constatan los datos del IAE anteriormente analizados, que señalan el auge del sector turismo en Béjar. Segunda, mientras que su importancia a nivel local es elevada, esto no es el caso a escala nacional. Tercera, todos los municipios mencionados aumentaron su Índice Turístico, lo que prueba la orientación generalizada en la provincia de Salamanca hacia el sector turismo. Cuarta, la distancia relativamente amplia con respecto a la ciudad de Salamanca supone una desventaja comparativa del sector turismo en Béjar frente a otros municipios próximos.

\section{EL MARKETING DEL TURISMO EN BÉJAR.}

\section{La organización institucional del sector.}

Actualmente hay dos instituciones que se reparten la organización del turismo en Béjar: la Agencia de Desarrollo Local y la Oficina de Turismo; además proyectan la creación de un nuevo centro de recepción de visitantes.

Los objetivos principales de la Agencia de Desarrollo Local son la planificación y la promoción del turismo. Desarrollan, entre otras actividades, nuevos proyectos turísticos, buscan medidas de financiación para ellos y organizan la promoción de Béjar en varias ferias turísticas. La Oficina de Turismo, por otro lado, se encarga de atender a los turistas que vienen a visitar Béjar. Les facilitan información sobre la ciudad, los diferentes lugares de interés, el alojamiento y las actividades que se pueden realizar en Béjar y sus alrededores. Adicionalmente, existen planes para la creación de un centro de recepción en la antigua estación de ferrocarril. En este centro pretenden ampliar y mejorar la oferta de información para los visitantes y, además, incorporar una sección exclusivamente sobre el turismo de nieve en La Covatilla. Este proyecto, sin embargo, todavía se encuentra en una fase temprana de planificación (AGENCIA DE DesarRollo Local, 2009a; Oficina DE TURISMO, 2009a).

\section{Las medidas de promoción.}

Béjar emplea tres medios principales para promover el turismo: el primero es la página web del Ayuntamiento de Béjar (www.aytobejar.com), donde se ofrece una sección dedicada al turismo, que contiene información sobre la ciudad, los monumentos principales, algunas tradiciones y ferias, los museos, rutas turísticas y la Sierra de Béjar. La cantidad de información varía mucho dependiendo de los diferentes temas tratados, pero generalmente ofrece una vista general aceptable. Aparte de esta página web oficial, se puede consultar otra de carácter privado (http://www.i-bejar.com/), que muestra informaciones parecidas $\mathrm{y}$, a menudo, más detalladas. Además informa sobre el alojamiento, los restaurantes y noticias actuales de Béjar (AYUNTAMIENTO DE BÉJAR, 2004; IBÉJAR, 2009). 
El segundo medio de promoción son los cuadernos, folletos y guías en soporte de papel. Estos contienen básicamente las mismas informaciones que dichas páginas web, aunque más detalladas y, obviamente, con la posibilidad de servir como guía al turista durante la visita a la ciudad. La Oficina de Turismo en Béjar dispone de estos y los facilita al visitante gratuitamente (OFICINA DE TURISMO, 2009a).

Por último, hay que mencionar las ferias de turismo en las que ha estado presente, concretamente, la Feria del Turismo de Interior, celebrada por última vez entre el 27 y el 30 de noviembre de 2008 en Valladolid; y la Feria Internacional de Lisboa, entre el 21 y el 25 de enero de 2009 (AGENCIA DE DESARROLLO LOCAL, 2009a).

\section{La financiación de la promoción turística.}

La financiación de las actividades de promoción turística procede de diversas fuentes: el Ayuntamiento de Béjar, la Junta de Castilla y León, el Gobierno Español y la Unión Europea. No hay datos disponibles sobre la cantidad exacta o la composición de los fondos, pero, según la Agencia de Desarrollo, los fondos municipales son bastante escasos y la mayoría de las actividades dependen de otras subvenciones externas. Por eso, la orientación de las actividades depende de las subvenciones, o sea, se desarrollan casi exclusivamente proyectos para los que pueden solicitar y recibir subvenciones (AGENCIA DE DESARROLLO LOCAL, 2009a). Esto conlleva una situación en la que la financiación de las actividades turísticas solamente está garantizada a corto plazo y se distingue para cada proyecto, lo cual dificulta una planificación coherente de actividades continuadas y homogéneas.

\section{EL MERCADO TURÍSTICO DE BÉJAR.}

\section{Los productos turísticos.}

La oferta turística en Béjar se orienta principalmente hacia tres tipos distintos de turismo: el turismo de interés cultural e histórico, el turismo de naturaleza y, desde la inauguración de la estación de esquí La Covatilla, el turismo de nieve. Describimos, ahora, los principales productos turísticos que ofrece Béjar en estos tres sectores, así como los proyectos futuros que se están desarrollando. En el caso del turismo de nieve, analizamos, además, los impactos que tiene la estación de esquí sobre el turismo en Béjar, dado que la misma no se localiza dentro de su término municipal.

a) El turismo cultural. 
Según la Oficina de Turismo y la Agencia de Desarrollo Local, el lugar de interés cultural e histórico más frecuentado en Béjar es el jardín histórico El Bosque. Fue construido en 1567 por el duque de Béjar, Francisco de Zúñiga y Sotomayor, como una villa suburbana de recreo. Se compone de una zona residencial y un amplio parque forestal de estilo italiano renacentista. Siendo en origen la residencia de verano del duque, hoy en día es propiedad pública y está abierta a los visitantes (Cf. FIGURA 2) (AYUNTAMIENTO DE BÉJAR, sin fecha/a; OFICINA DE TURISMO, 2009a).

Aparte de El Bosque, el Palacio Ducal es otra herencia de los Zúñiga que se ha convertido en lugar de interés turístico. Este palacio fue construido en el siglo XVI sobre los restos de un antiguo castillo. Desde el año 1931 está declarado Bien de Interés Cultural con la categoría de Monumento. Actualmente, los turistas pueden visitar el patio de estilo renacentista, así como algunas estancias del edificio (AYUNTAMIENTO DE BÉJAR, sin fecha; OFICINA DE TURISMO, 2009a). La ubicación de El Bosque, del Palacio Ducal, así como de los demás sitios principales de interés turístico, está representada en la FIGURA 6.

Figura 2. Jardín histórico El Bosque

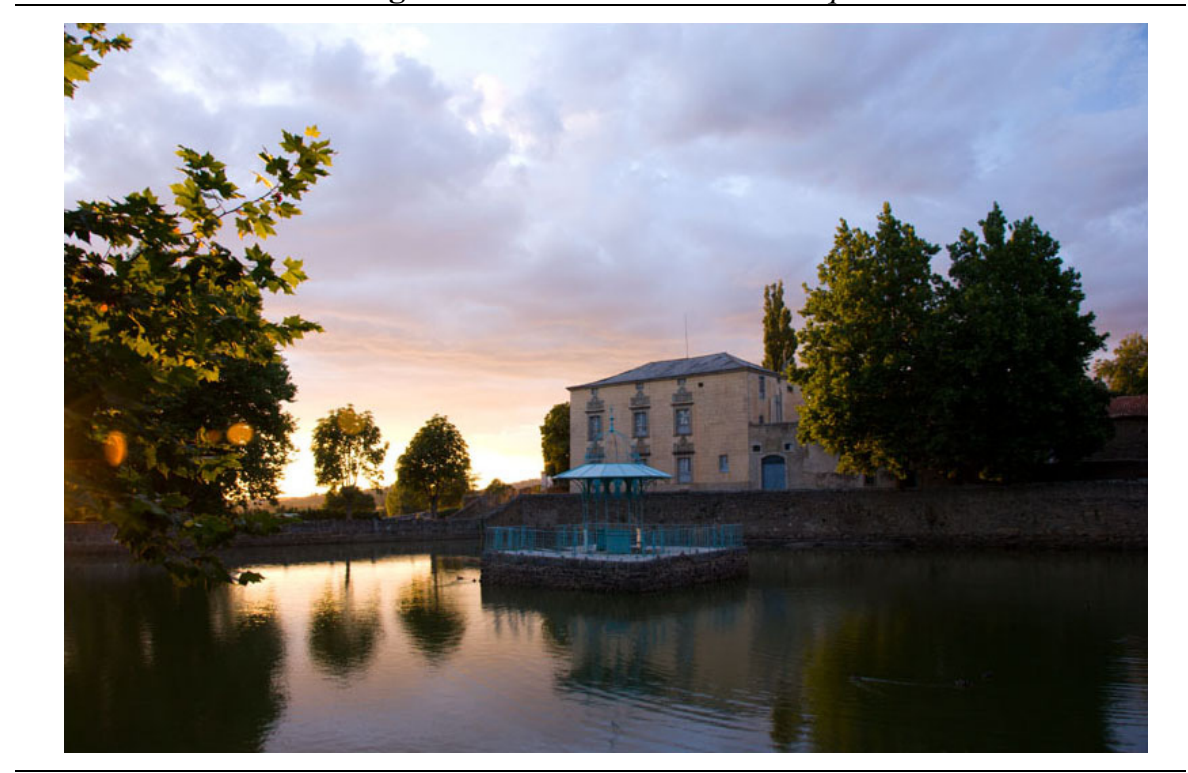

FUENTE: Fotógrafo desconocido, 2008

(http://www.flickr.com/photos/publikaccion/2945923901/in/set-72157608072199528/)

Otro lugar de interés destacable es la plaza de toros, que se considera la más antigua aún existente de toda España (Cf. FIGURA 3). Originalmente construida 
en 1667, se inauguró de forma oficial en 1711; la última restauración data del año 1962. En la actualidad, al lado de la plaza se encuentra el museo taurino, donde se exponen diversos objetos relacionados con la historia torera en Béjar (AYUNTAMIENTO DE BÉJAR, 2004).

Aparte de este museo, hay tres más en la ciudad: el museo municipal Mateo Hernández, el museo municipal Legado Valeriano Salas y el Museo Judío David Melul. En el museo municipal Mateo Hernández, inaugurado en 1980, se exhiben 51 esculturas del homónimo artista bejarano, así como algunas más de otro escultor local, Francisco González Macías (AYUNTAMIENTO DE BÉJAR, sin fecha/a; AYUNTAMIENTO DE BÉJAR, sin fecha/c). El museo municipal Legado Valeriano Salas reúne obras de pintura española y europea, así como arte oriental y artes industriales de Europa. Todas las obras, originalmente coleccionadas por Valeriano Salas durante sus numerosos viajes, las donó su viuda tras la muerte de su marido en 1962 a favor del municipio de Béjar (AYUNTAMIENTO DE BÉJAR, 2004; AYUNTAMIENTO DE BÉJAR, sin fecha/b). Por último, el Museo Judio David Melul expone objetos relacionados con la tradición de la población judía en la Península hasta su expulsión en el año 1492, la vida y la cultura de los conversos en la España cristiana, así como de los judíos que se marcharon al exilio (MUSEO JUDÍO DAVID MELUL, 2009).

Figura 3. Vista del interior de la plaza de toros

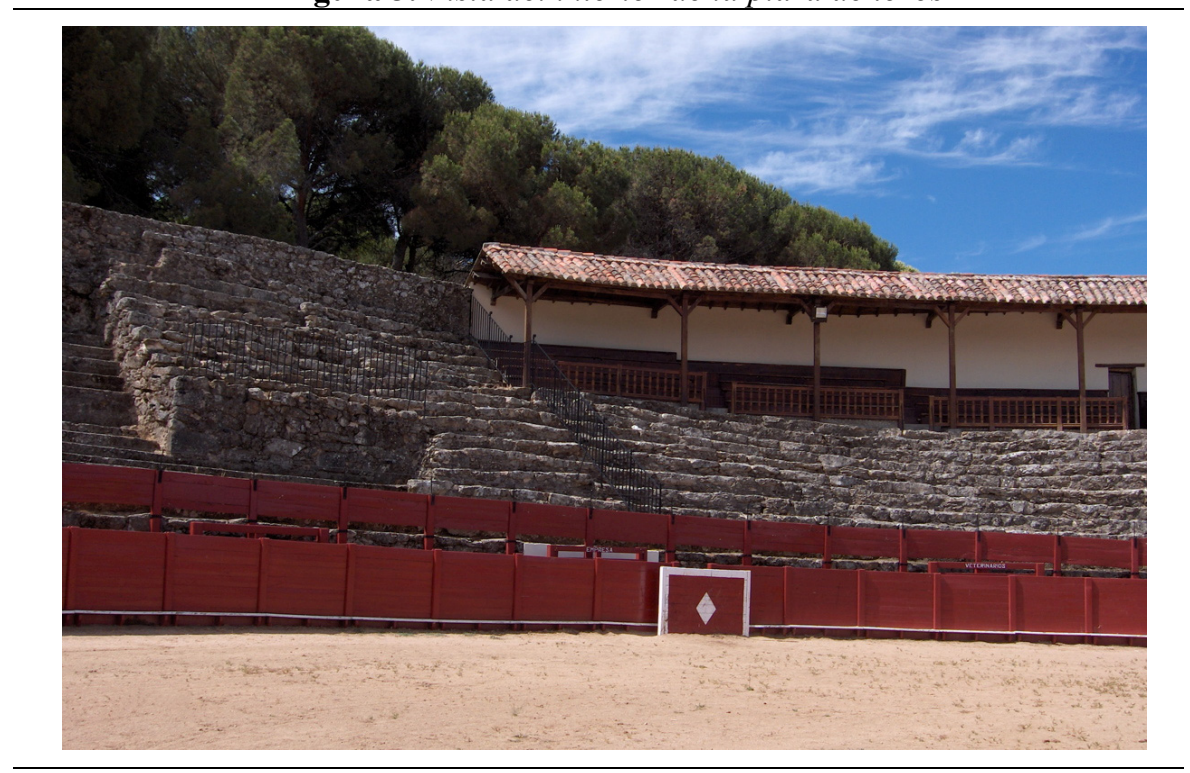

FUENTE: Barragán, 2005

(http://www.panoramio.com/photo/11692322) 
Así mismo, se está utilizando el patrimonio histórico industrial para el turismo. En este sentido han reconvertido varias fábricas abandonadas en la ribera del río Cuerpo de Hombre en un tipo de museo al aire libre, llamado la Ruta de las Fábricas Textiles. Esta ruta es un paseo de aproximadamente 4 kilómetros señalizado y con paneles explicativos sobre las diferentes fábricas que se ubican en la zona. Dentro de la misma se está creando, además, en la antigua fábrica de Gilart Fité el Museo Textil (Cf. FIGURA 4), cuya inauguración fue planeada originalmente para el año 2004, pero debido a problemas de financiación aún no está abierto al público (AYUNTAMIENTO DE BÉJAR, sin fecha/d; AYUNTAMIENTO DE BÉJAR, 2004; TRIBUNA DE SALAMANCA, 2009). Otras rutas turísticas se realizan en cooperación con distintos municipios, entre ellos la Ruta de los Conjuntos Históricos de la Provincia de Salamanca y la Ruta Vía de la Plata.

Figura 4. El futuro Museo Textil como parte de la Ruta de las Fábricas

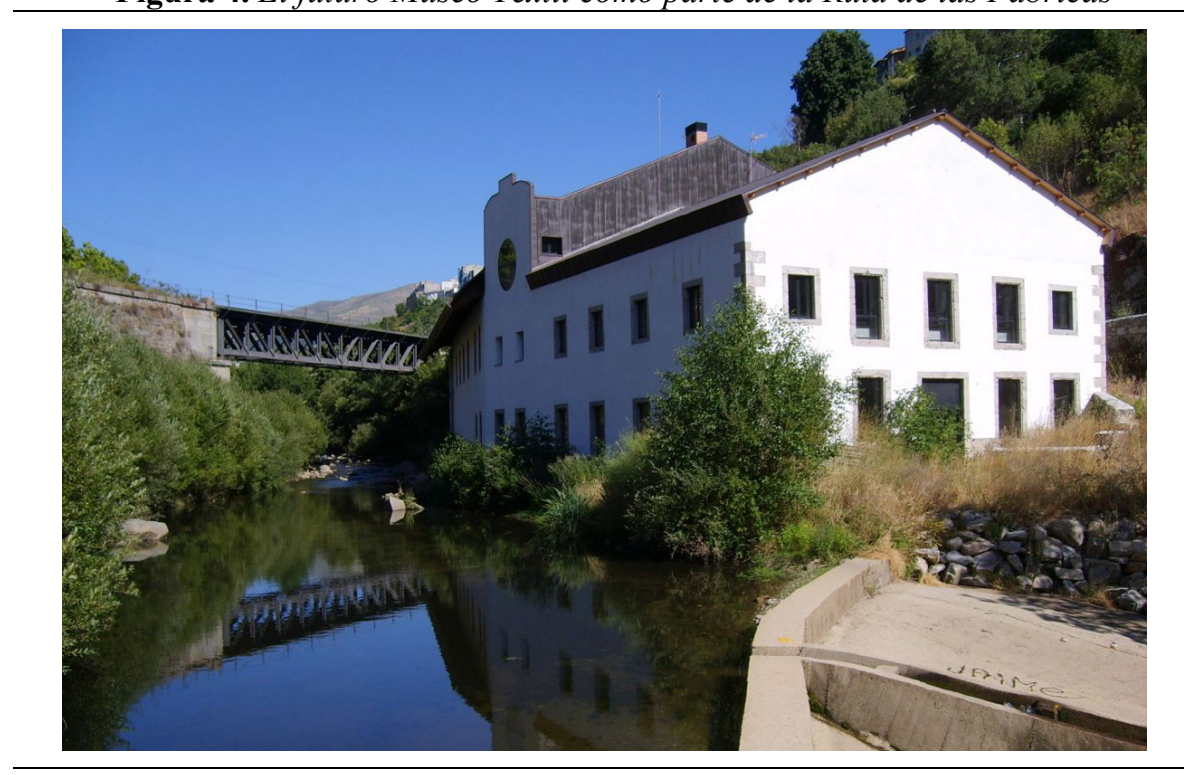

FUENTE: Fotógrafo desconocido, 2008

(http://www.flickr.com/photos/lince_rojo/2817483840/)

Además de los mencionados lugares de interés principales, cabe subrayar que el casco histórico de Béjar (Cf. FIGURA 5) dispone de un patrimonio arquitectónico considerable. Este no solamente se limita a los edificios destacables como el Convento de San Francisco o la Iglesia de Santa María de Mayor, ambos parte de la herencia eclesiástica, al Teatro Cervantes o a los restos de las murallas medievales. Más bien, se plasma en la arquitectura de los edificios en conjunto, así como en las callejuelas estrechas y de varios rincones, las cuales, de- 
bido al medio físico, a menudo presentan un fuerte desnivel e incluso parcialmente se convierten en escaleras. Fuera del casco histórico, la presencia de edificios del sistema textil, bien en uso o bien abandonados, caracterizan el aspecto urbano, lo que demuestra la importancia de esta industria para la ciudad de Béjar en la historia reciente y su vínculo estrecho con ella (ALONSO SANTOS ET AL., 1995; JCYL, 2009, 19; AYUNTAMIENTO DE BÉJAR, 2004).

Figura 5. La arquitectura del casco histórico de Béjar

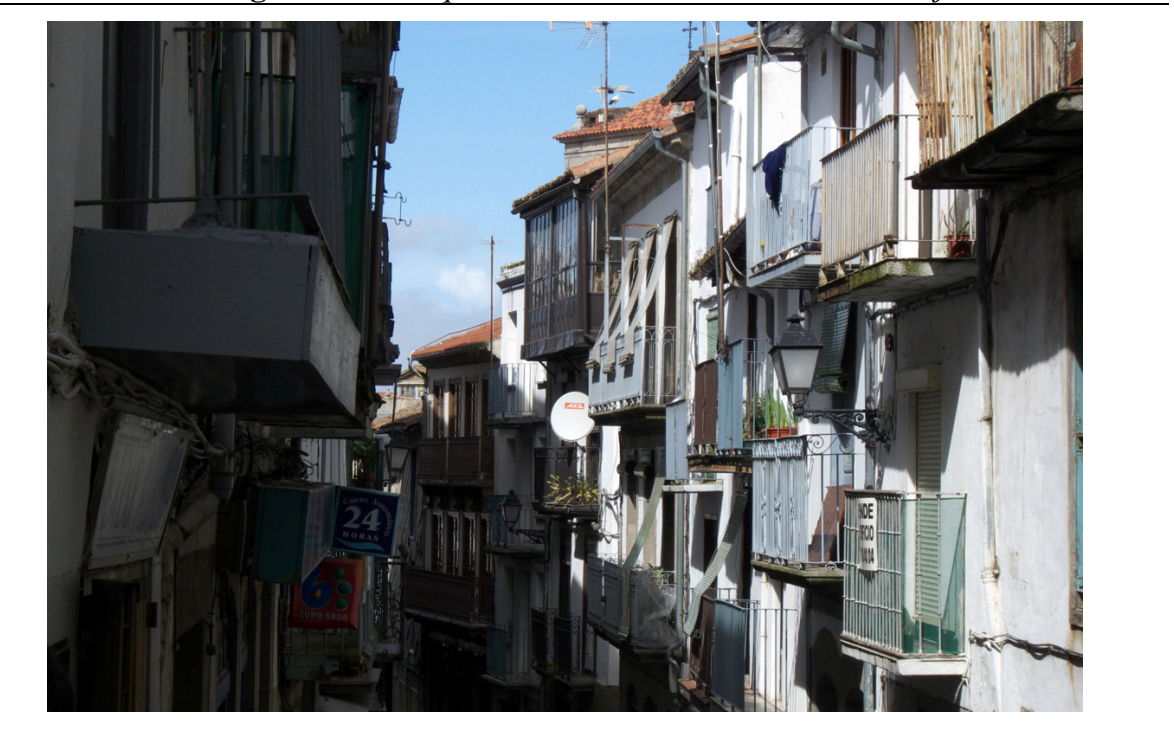

FUENTE: Brossmann, 2010

Tanto el casco antiguo como la arquitectura industrial del siglo XX le facilita al visitante una visión de la identidad local bejarana, por lo cual, en conjunto, puede considerarse como espacio de interés turístico. Sin embargo, los dos conjuntos demuestran, en parte, fuertes signos de deterioro y desmoronamiento, lo que limita la atracción turística de estos espacios notablemente. Además, hasta la fecha, el Ayuntamiento no ha incluido ninguna de las dos zonas urbanas en la promoción del turismo, sino que pone énfasis en aquellas atracciones principales y de mayor interés turístico que mencionamos anteriormente (JCYL, 2009, 21; AYUNTAMIENTO DE BÉJAR, 2004).

En lo referente al turismo cultural, falta mencionar, por último, las diversas fiestas tradicionales, que se celebran en Béjar en el curso del año y que igualmente atraen visitantes. Entre ellas, la Semana Santa, las fiestas de la Virgen del Castañar y la fiesta del Corpus Christi son las más frecuentadas por los turistas (OFICINA DE TURISMO, 2009b). 
Figura 6. La distribución de los principales sitios de interés turísticos en el espacio urbano de Béjar

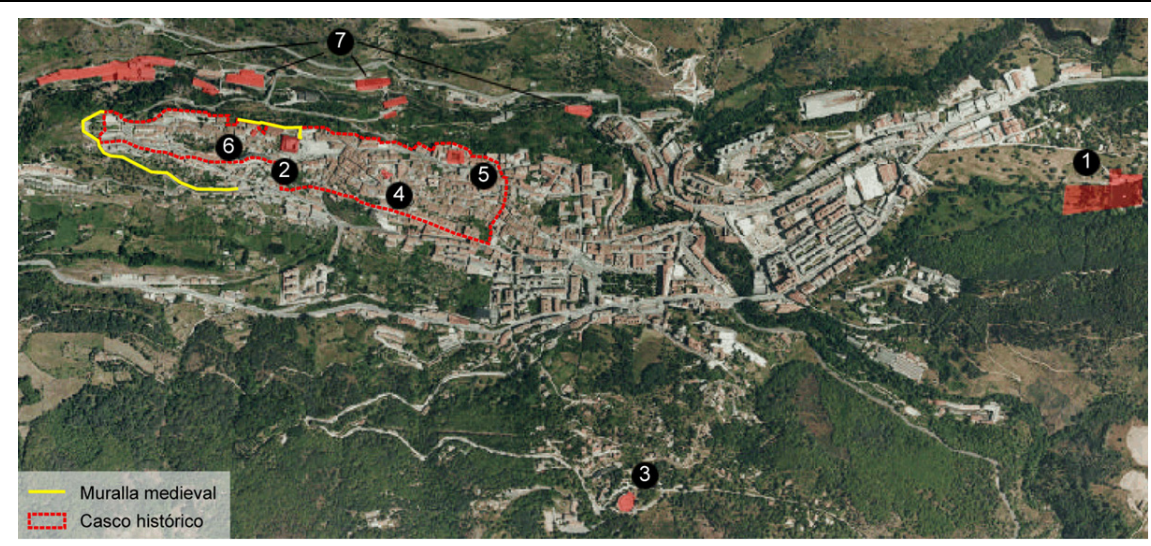

1) El Bosque 2) Palacio Ducal 3) Plaza de toros y museo taurino 4) Museo Mateo Hernández 5) Museo Legado Valeriano Salas 6) Museo Judío David Melul 7) Ruta de las Fábricas Textiles

FUENTE: Elaboración propia a partir de SITCYL, 2009

\section{b) El turismo de naturaleza.}

En cuanto a la actividad turística relacionada con la naturaleza, Béjar se beneficia fuertemente de su ubicación en la sierra del mismo nombre, cuyo paisaje montañoso y variado destaca entre las penillanuras tanto de Extremadura como de Castilla, que ofrecen una imagen más uniforme. Como parte del espinazo del Sistema Central, morfológicamente la Sierra de Béjar se divide en sierras elevadas, fosas internas y valles - un modelo común en el Sistema Central que se conoce como las "teclas de piano" (LUENGO UGIDOS ET AL., 1995a). Dichas grandes diferencias de altura, junto a la situación climática, que se caracteriza por la influencia tanto del clima atlántico como del mediterráneo, provocan que esta zona tenga una gran diversidad paisajística y natural (LUENGO UGIDOS ET AL., 1995a). Aparte del medio físico, el entorno de Béjar revela, además, un alto valor en términos eco-culturales, que radica en el ambiente de los pequeños pueblos de la Sierra, así como en las actividades ganaderas, ocupando alrededor de la mitad de la superficie y, en menor parte, agrarias. (LUENGO UGIDOS ET AL., 1995b).

El Ayuntamiento de Béjar trata de aprovechar estos recursos naturales y ecoculturales, sobre todo, promoviendo rutas de senderismo. Gracias a su ubicación en la Sierra y puesto que es el mayor asentamiento de la comarca, la ciudad sirve como punto de partida para éstas y cuenta con una infraestructura adecuada para alojar a los turistas de naturaleza (Cf. apartado IV.2). En su promoción del turismo de naturaleza el Ayuntamiento destaca que la Sierra de Béjar es un 
"contrapunto paisajístico" (DIPUTACIÓN DE SALAMANCA, sin fecha) a la ciudad de Salamanca con el fin de poner de relieve el valor que tiene su entorno y aumentar así el número de turistas. Las rutas sobre las que facilitan información en la Oficina de Turismo tienen una gran diversidad en lo referente a su duración y dificultad. Las más fáciles tienen una duración de una hora con un desnivel de $150 \mathrm{~m}$, para las más avanzadas hay que contar con una ida de 7 horas y $1.435 \mathrm{~m}$ de desnivel (DIPUTACIÓN DE SALAMANCA, sin fecha; AYUNTAMIENTO DE BÉJAR, 2004).

c) El turismo de nieve.

La tradición de la práctica del esquí en la Sierra de Béjar ya existe desde finales de los años 1920. Sin embargo, hasta los últimos años del siglo XX, no desarrollaron el potencial para un turismo de nieve. No fue hasta 1994 cuando el Ayuntamiento de Béjar, en cooperación con la Unión Europea, aprobó un Plan Operativo Local que permitió la instalación de infraestructuras adecuadas destinadas al turismo de nieve con importancia suprarregional. La estación de esquí en su forma actual fue inaugurada en 2002 y se encuentra en el sureste de Béjar, a unos 18 kilómetros siguiendo la conexión viaria (Cf. FIGURA 7) (SEGADE ILLÁN, 2005, 3).

Figura 7. Ubicación de la estación de esquí La Covatilla

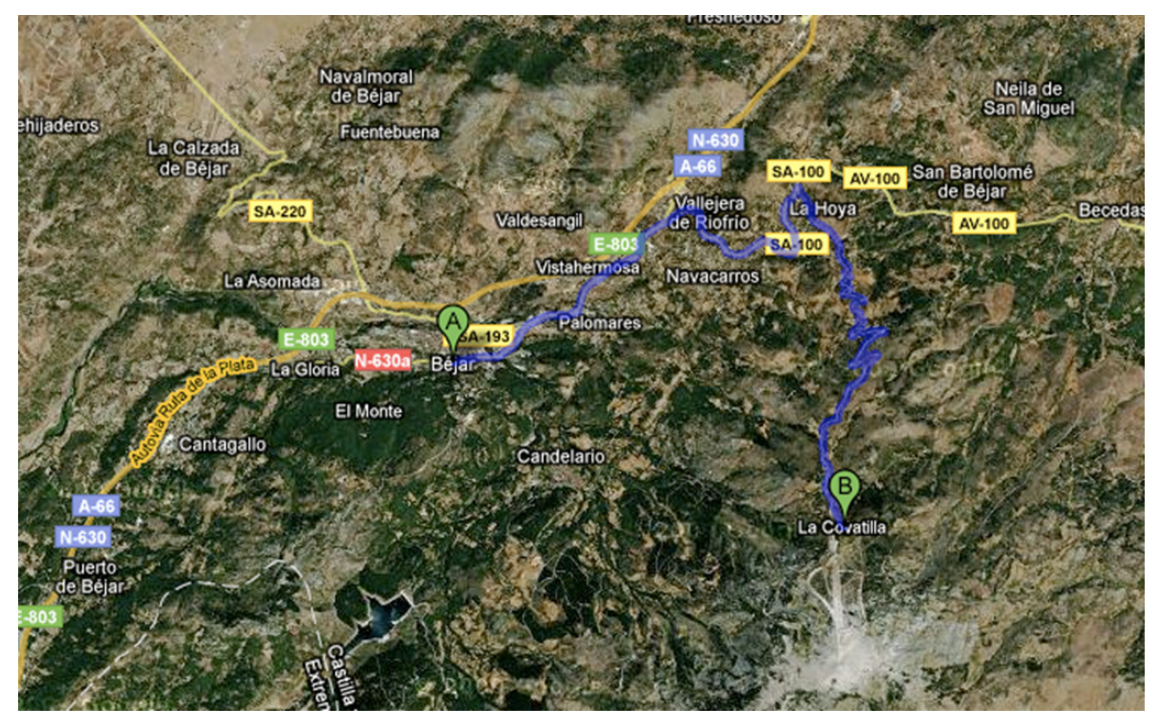

FUENTE: Google Mapas, 2009

La esperanza del Ayuntamiento de Béjar era que dicha estación generara un impulso fuerte para el turismo en la ciudad. Ocho años después de su apertura, 
sin embargo, hay opiniones contrapuestas sobre el beneficio de La Covatilla. Las críticas no solamente se dirigen al impacto sobre el medio ambiente (estas críticas ya existen desde los inicios del proyecto), sino también al beneficio real para el turismo en Béjar. Tratamos, ahora, de evaluar este impacto en el sector turismo.

Desde su inauguración en el año 2002, el balance de La Covatilla en cuanto a visitantes recibidos ha fluctuado mucho. Mientras que las oscilaciones del número total de esquiadores se explican en parte por los diferentes días de apertura anual, la cuota de esquiadores al día de apertura no depende de dicha variable. Esta cuota muestra que la popularidad de La Covatilla ha aumentado, pero de forma desigual y con un fuerte descenso en la temporada 2006/2007. El siguiente cuadro da una visión conjunta sobre el flujo de visitantes:

Cuadro 2. Esquiadores en La Covatilla

\begin{tabular}{lrrr}
\hline Temporada & $\begin{array}{r}\text { Días de } \\
\text { apertura }\end{array}$ & $\begin{array}{r}\text { Esquiadores } \\
\text { Total }\end{array}$ & Esquiadores/dia \\
\hline 2002 & 73 & 17.441 & 239 \\
$2002 / 2003$ & 107 & 24.387 & 228 \\
$2003 / 2004$ & 125 & 32.200 & 258 \\
$2004 / 2005$ & 86 & 30.749 & 358 \\
$2005 / 2006$ & 138 & 76.593 & 555 \\
$2006 / 2007$ & 108 & 30.779 & 285 \\
$2007 / 2008$ & 113 & 58.371 & 517 \\
$2008 / 2009$ & 144 & 94.419 & 656 \\
\hline
\end{tabular}

FUENTE: Elaboración propia a partir de GECOBESA, 2009

Ahora bien, para evaluar el beneficio en el turismo bejarano, hay que analizar el comportamiento de los esquiadores más detalladamente en lo referente a los días de estancia y, si pernoctan, atender al lugar del alojamiento. La base de este análisis la constituye una serie de entrevistas realizadas en la temporada 2007/2008 por Gecobesa, la gestora de La Covatilla. Lamentablemente no mencionan la cantidad exacta de entrevistas, sino simplemente que entrevistaron a "más de un millar" (GECOBESA, 2008, 14) de esquiadores. Según estas entrevistas, la gran mayoría de los encuestados (un 70,5 \%) sólo permanece en la estación de esquí durante un día; si se consideran todos los que esquían tres días o menos, el porcentaje se eleva incluso a un 94,9\%. Por ello, resulta evidente que se trata de turismo de corta duración. Del total de los esquiadores, el 26,1 \% se queda más de un día y pernocta en la zona fuera de su propia casa. Entre ellos, el 30,7\% se aloja en Béjar, lo que significa que es el lugar más frecuentado para el alojamiento. En números absolutos, este porcentaje equivale a 4.676 
pernoctaciones en Béjar durante la temporada 2007/2008 (GECOBESA, 2008, 17).

Se pueden interpretar estos datos desde dos perspectivas. Por un lado, la ciudad recibe más de 4.000 turistas en una estación del año en la que casi no hay otras actividades turísticas. Dado que, según los datos de la Oficina de Turismo en Béjar, los visitantes vinculados con el turismo de nieve suponen el $85 \%$ del total en invierno, resulta que La Covatilla es muy importante para el turismo bejarano durante esta estación. Por otro, tan sólo el $8 \%$ de los esquiadores de la Covatilla pernocta en Béjar. Esto significa que la ciudad solamente participa en una pequeña parte del potencial turístico que genera la estación de esquí. Además, la variabilidad climática, que influye en los días de apertura y, por lo tanto, en el número total de esquiadores, es un factor de inseguridad ya que no se puede prever ni planificar.

\section{d) Proyectos futuros.}

En la actualidad el Ayuntamiento lleva a cabo varios proyectos para fomentar el turismo en Béjar. Estos proyectos, que están en diferentes fases de aprobación, no se enfocan en la generación de nuevas atracciones turísticas, sino más bien en la mejora del potencial turístico ya existente. En este sentido, pretenden ampliar y renovar la señalización dentro de la ciudad, en los senderos de montaña, así como en la Ruta de las Fábricas Textiles. Igualmente, planean generar una audio-guía en formato $\mathrm{mp} 3$, que se pueda descargar gratuitamente y que contenga las informaciones más importantes sobre los diferentes lugares de interés. En cuanto al museo municipal Mateo Hernández, no sólo quieren implementar dichas medidas de señalización y de oferta de audio-guía, sino también instalar sistemas de aire acondicionado. Esto tiene como finalidad exponer algunas obras de Mateo Hernández que necesitan ciertas condiciones climáticas y que todavía se encuentran en el Museo Nacional Centro de Arte Reina Sofia. Otros proyectos son la apertura de la torre septentrional del Palacio Ducal para el turismo y la rehabilitación de la plaza de toros (AGENCIA DE DESARROLLO, 2009b; AYUNTAMIENTO DE BÉJAR, 2004).

\section{Las infraestructuras turísticas.}

Béjar dispone de una infraestructura relativamente amplia de alojamiento. En total la capacidad en la ciudad y el entorno inmediato se eleva a unas 800 plazas, que se distribuyen entre los diferentes tipos de alojamiento. Mientras que dos hoteles de categoría *** en el centro urbano de Béjar y uno cercano a la ciudad se ocupan de las necesidades del turismo de calidad, varias pensiones, hospederías, hostales y albergues ofrecen pernoctaciones de todo tipo de precio. Aparte del alojamiento dentro del casco urbano, también existe la posibilidad de 
alquilar casas rurales en los alrededores de Béjar. Estas casas habitualmente tienen entre seis y ocho camas y se dirigen a las necesidades de visitantes que buscan un turismo de naturaleza (JCYL, 2007, 18; OFICINA DE TURISMO, 2009a).

En cuanto a la restauración, la oferta es igualmente amplia. Además de una gran cantidad de restaurantes de categoría media y baja, hay seis de categoría más elevada, que disponen juntos de un total de 1.067 plazas (JCYL, 2007). Sin embargo, según los datos de Caja España y de acuerdo con los del IAE que facilitó la Cámara de Comercio, el número total de cafés y bares ha disminuido un $20 \%$ en los últimos años (CAJA ESPAÑA, 2009; IAE, 1999; IAE, 2008).

La mayoría de los comercios de hostelería y restauración forman parte de la Asociación de Empresarios de Béjar y Comarca (EMBECO). No obstante, la cooperación entre sí se limita a una posición representativa en situaciones conflictivas, como es el caso del debate sobre el beneficio de La Covatilla. Ni hay un intercambio oficial de conocimientos o experiencia a través de EMBECO, ni desarrollan estrategias comunes (EMBECO, 2009).

En lo que se refiere a proyectos futuros de la infraestructura turística, hay que mencionar, sobre todo, la construcción planteada de un Parador Nacional de Turismo; este Parador tendrá una capacidad de 80 habitaciones de categoría alta. La ubicación prevista es la finca La Cerrallana. Sin embargo, el proyecto aún no está aprobado. El plan parcial correspondiente se encuentra en la fase de exposición pública (I-BÉJAR, 2009; PARADORES DE TURISMO, S.A., 2009).

\section{La demanda turística.}

Tras la caracterización y el análisis de los productos turísticos, así como la infraestructura turística que ofrece Béjar, es decir, dos aspectos que se refieren a la oferta en este sector, es necesario, además, contemplar el otro determinante en el mercado turístico: la demanda. Examinamos, por lo tanto, la cantidad y el tipo de visitantes que hacen uso de este potencial turístico para poner de manifiesto las características de los turistas que van a Béjar. Como fuente utilizamos las encuestas que la Oficina de Turismo llevó a cabo en el año 2008.

En ese año, 30.413 personas consultaron la Oficina de Turismo para obtener informaciones de cualquier tipo relacionadas con el turismo. En este número también se incluyen las consultas realizadas por vecinos de la propia localidad (el 21,5\%), las telefónicas (el 6,2 \%) y los visitantes que solamente recogieron material sin pernoctar o visitar los sitios sobre los que se habían informado anteriormente. Por eso, no se puede deducir un número absoluto sobre los turistas que recibe Béjar al año; sin embargo, en términos relativos, sí que son valiosos estos datos (OFICINA DE TURISMO, 2009a; OFICINA DE TURISMO, 2009c). 
En lo que respecta a la distribución por estaciones del año, resulta evidente que el verano (Julio, Agosto y Septiembre reúnen el 40,1 \%) y el mes de marzo (el 14,3\%) son los períodos más frecuentados en Béjar. Durante el verano destaca sobre todo Agosto con un 18,4\%. En cuanto al origen de los visitantes, se trata casi exclusivamente de un turismo nacional; tan sólo el 6,8 \% proviene del extranjero. Dentro de las diferentes comunidades autónomas, Madrid tiene la posición principal, seguido por Castilla y León y Andalucía. Si combinamos las dos variables mencionadas, destaca que especialmente los turistas con origen de comunidades autónomas más lejanas como el País Vasco, Cataluña o la Comunidad Valenciana concentran su estancia en Béjar en los meses veraniegos. Las tendencias de los visitantes de las comunidades más cercanas, así como del extranjero, son más equilibradas durante el año (OFICINA DE TURISMO, 2009c).

Aparte de estos datos cuantitativos, la Oficina de Turismo también recogió algunas informaciones cualitativas sobre la demanda turística. Como ya mencionamos anteriormente, las tres actividades principales son el turismo cultural e histórico, el turismo de naturaleza y el turismo de nieve. Mientras que el último se concentra, obviamente, en los meses de invierno, los otros dos se realizan sobre todo entre primavera y otoño. Fuera de los períodos de vacaciones de verano y de la Semana Santa, el turismo se concentra en su mayoría durante los fines de semana; los turistas suelen pernoctar 1 ó 2 noches. El grupo de turistas más numeroso en cuanto a la edad y la situación económica es la clase media entre 30 y 60 años (OFICINA DE TURISMO, 2009c).

\section{CONCLUSIONES}

\section{El sector turismo en Béjar comparado con su papel en el marco con- ceptual}

Al comparar el papel que desempeña el sector turismo en las políticas urbanas y la economía local bejarana con su posición en el concepto teórico de las nuevas políticas urbanas, resulta que hay diversas características comunes.

El Ayuntamiento de Béjar asigna al turismo una posición central para la diversificación de la economía local y la atracción de recursos externos. Las autoridades locales son conscientes de la necesidad de revalorizar el espacio urbano para desarrollar y fomentar el potencial turístico con el que cuenta la ciudad; pretenden, por lo tanto, generar valores turísticos y transformarlos en nuevas fuentes de ingresos para la economía local. En este sentido rehabilitan su patrimonio cultural, tanto de períodos históricos más lejanos (entre otras cosas $E l$ Bosque, el palacio ducal y la plaza de toros), como de la historia reciente que estaba determinada por la industria textil. Proyectos como la Ruta de las Fábricas Textiles muestran que Béjar tiene la intención de integrar su tradicional y 
fuerte vinculación con la industria textil en la nueva imagen turística y conservar, así, su identidad relacionada estrechamente con la tradición lanera. Los agentes públicos, representados por la Oficina de Turismo y la Agencia de Desarrollo Local, están involucrados activamente en este proceso. Sobre todo la última tiene un papel crucial, dado que planifica y coordina las estrategias turísticas y el marketing urbano. Sin embargo, como los proyectos futuros mencionados anteriormente demuestran, la agencia no solamente trata de crear una imagen positiva al exterior mediante medidas de marketing, sino que también intenta mejorar la oferta y la infraestructura turística cualitativamente. Todas estas medidas contribuyen a la consolidación y ampliación del sector turismo en la economía local y coinciden en su mayor parte con el marco conceptual.

Hay que tener en cuenta, sin embargo, que, debido al tamaño pequeño de la ciudad y la ausencia de atractivos turísticos destacables con importancia suprarregional dentro de ella, la ejecución de las medidas mencionadas se lleva a cabo a escala reducida. El patrimonio histórico no es tan numeroso como para generar una atracción turística de modo que posibilite la creación de zonas culturales considerables. Aunque la conversión de partes del patrimonio en museos tenga éxito, como en el caso de algunas fábricas textiles, y aumente el valor turístico de la ciudad, es dudoso que exista una demanda suficientemente considerable de teatros, centros culturales o de congresos que justifique su instalación a escala mayor. Es decir, un aumento amplio de la oferta de las actividades mencionadas en el marco conceptual relativas al turismo muy probablemente no encontraría una demanda que permitiera un funcionamiento económicamente rentable. No obstante, haría falta exactamente la instalación de estas zonas culturales y de ocio para aumentar la importancia del turismo de un modo significativo.

Por todo ello, concluimos que el sector turismo en Béjar desempeña un papel que coincide en muchos aspectos con el modelo teórico, pero las limitaciones derivadas del pequeño tamaño de la ciudad y de su patrimonio histórico impiden la implantación de las medidas en todas las facetas y con la escala o magnitud que se contemplan en el marco conceptual.

\section{El turismo en Béjar - ¿Un sector con futuro?}

En los últimos años, la trayectoria del sector turístico en Béjar ha sido muy positiva. Tanto a nivel municipal como en consideración dentro del ámbito nacional se ha incrementado su importancia y, según los datos disponibles, aún está creciendo a día de hoy. Este avance, sin embargo, se basa, sobre todo, en los cambios de las políticas urbanas que atribuyen al sector turismo una posición central en la economía bejarana; en este sentido, se han desarrollado estructuras para aprovechar mejor el potencial turístico. Cabe preguntarse, por lo 
tanto, si el turismo puede continuar creciendo en el futuro, dado que buena parte del potencial turístico de Béjar ya está desarrollado.

Como mencionamos anteriormente, a pesar de los esfuerzos en este sector, a escala nacional el turismo bejarano sigue teniendo una posición muy marginal. Esto no cambiará significativamente en el futuro, porque el potencial turístico, especialmente el cultural y de interés histórico, tiene sus limitaciones. Aunque el Municipio pretende mejorar la oferta en este ámbito con proyectos como el de la Ruta de las Fábricas Textiles, no aumentará la atracción suficientemente de manera que pueda competir con ciudades de mayor interés cultural como Salamanca. Además, Béjar no es la única ciudad que aplica las nuevas políticas urbanas, por eso la competencia en cuanto a la oferta turística aumenta, mientras que la demanda no lo hace o solamente en menor medida. Otra desventaja es la distancia relativamente larga al centro turístico de la provincia, la ciudad de Salamanca. Como se puede observar en los casos de Santa Marta de Tormes y Villamayor, la proximidad a Salamanca les permite aprovecharse de un potencial turístico que no es el propio. En lo que respecta a la organización y promoción del turismo, la financiación basada en subvenciones externas supone el riesgo principal. La dependencia que se genera debido a este modo de financiación dificulta una planificación continuada y homogénea; por eso, la creación de un perfil turístico propio es más difícil.

A pesar de todo esto, Béjar sí que tiene algunas posibilidades de mejorar su posición como destino turístico. De las tres actividades principales, las de la naturaleza albergan las mejores posibilidades de crecimiento. Por un lado, porque el turismo ecológico y de naturaleza está en auge a escala global. Por otro, porque Béjar tiene una ventaja comparativa respecto a otros municipios: la Sierra de Béjar. En este sentido, la ciudad podría enfocar más el turismo hacia actividades relacionadas con la montaña y, así, crear un perfil que describa Béjar principalmente como punto de partida para un turista de naturaleza, que, además, disponga de cierto interés cultural. En cuanto al turismo de nieve, se podría intentar aumentar la vinculación entre La Covatilla y la ciudad de Béjar para atraer un porcentaje más alto de esquiadores. Proyectos como la instalación de una línea de autobuses a La Covatilla, realizada a principios de 2009, o la incorporación de una sección informativa sobre la estación de esquí en el centro de recepción de visitantes proyectado son medidas que pueden reforzar esta vinculación. Hay que tener en cuenta, sin embargo, que la mayor parte del turismo de esquí en La Covatilla seguirá siendo de corta duración; por ello, el beneficio real de esta estación de esquí para Béjar no aumentará de forma destacada.

En cuanto al marketing del turismo se puede mejorar la presencia oficial en Internet. La página web del Ayuntamiento contiene informaciones generales de 
interés turístico, pero los textos datan del año 2004 y no hay información actual o práctica. No es posible encontrar listas de alojamiento, ni horarios o conexiones de los medios de transporte. La actualización del contenido y el mantenimiento regular de esta página proporcionarían una imagen más sugerente al visitante y, por ello, mejorarían la imagen al exterior.

En conclusión podemos afirmar que el sector turístico en Béjar seguirá creciendo en el futuro, pero no en la misma medida que lo ha hecho en los últimos años. Todavía hay potencial turístico que no se ha desarrollado completamente y del que Béjar se puede aprovechar. Sin embargo, los aspectos negativos mencionados muestran que el turismo bejarano tiene limitaciones y a largo plazo probablemente no podrá ser el sector fundamental de la economía local, sino que deberán articularse otras fuentes complementarias de empleo e ingresos.

\section{BIBLIOGRAFÍA.}

Alonso Santos, J. L. y J. L. SÁnchez Hernández (1995): Béjar. En: CABero DIEGUEZ, V. (Coord.): Salamanca y sus comarcas. Madrid, Editorial Mediterráneo, pp. 281-288.

BENITO DEL PozO, P. (2004): Discursos, propuestas y acciones sobre la ciudad postindustrial, Anales de Geografía de la Universidad Complutense, 24, pp. 9-29.

Benito Del Pozo, P. (2005): Pautas actuales de la relación entre industria y ciudad, Eria, 66, pp. 57-70.

CONNELLY, G. (2007): «Testing Governance - A research agenda for exploring Urban Tourism Competitiveness Policy: The Case of Liverpool 1980-2000». Tourism Geographies, 9, pp. 84-114.

LAw, C. M. (1992): Urban Tourism and its Contribution to Economic Regeneration. Urban Studies, 29, pp. 599-618.

LAw, C. M. (1996): Tourism in Major Cities. Londres, International Thomson Business Press.

Law, C. M. (2000): Urban tourism: Attracting Visitors to Large Cities. Londres, Mansell.

LAW, C. M. (2002): Urban tourism: the visitor economy and the growth of large cities. Londres, Continuum, $2^{\mathrm{a}}$ ed.

LEVINE, M. V. (2003): Tourism-based redevelopment and the fiscal crisis of the city: the case of Montreal. Canadian Journal of Urban Research, 12, pp. 102-123.

LuENGo Ugidos, M. A.; MARTín VÁZQUEZ, E. y M. J. SÁNCHEZ MuÑOZ (1995a): La Sierra de Béjar I. En: CABERo DiegueZ, V. (Coord.): Salamanca y sus comarcas. Madrid, Editorial Mediterráneo, pp. 265-272.

Luengo Ugidos, M. A.; MARTín VÁZQUEZ, E. y M. J. SÁNCHEZ MuÑoz (1995b): La Sierra de Béjar II. En: CABERo DiEgUEZ, V. (Coord.): Salamanca y sus comarcas. Madrid, Editorial Mediterráneo, pp. 273-280.

SÁNCHEZ HERNÁNDEZ, J. L.; APARICIO AMADOR, J. y V. RODERO GONZÁLEZ (2006): Las pequeñas ciudades industriales españolas: Economía, sociedad y nuevas políti- 
cas urbanas. En: MÉNDEZ, R. Y H. PASCUAL (Coords.): Industria y ciudad en España: nuevas realidades, nuevos retos. Madrid, Thomson-Civitas, pp. 465-492.

SÁNCHEZ HERNÁNDEZ, J. L. (2002): La industria textil en Béjar: Entre la crisis del empleo y la reestructuración productiva. En: MÉNDEZ, R. y J. L. ALONSO coords.: Sistemas locales de empresas y redes de innovación en Castilla-La Mancha y Castilla y León. Salamanca, Ediciones Universidad de Salamanca, pp. 153-174.

\section{FUENTES.}

Agencia de Desarrollo Local (2009a): Entrevistas con la Agencia de Desarrollo Local del Ayuntamiento de Béjar, 5/03/2009.

Agencia de Desarrollo Local (2009b): Entrevistas con la Agencia de Desarrollo Local del Ayuntamiento de Béjar, 27/03/2009.

AGRUPACIÓN DE FABRICANTES DE BÉJAR (2009): Entrevista con Cristino Bueno, secretario de la Agrupación de Fabricantes de Béjar (5.3.2009).

ASOCIACIÓN DE EMPRESARIOS DE BÉJAR Y COMARCA (EMBECO) (2009): Entrevista con la Asociación de Empresarios de Béjar y comarca (27.3.2009).

AyUnTAMiEnTo de BÉJAR (sin fecha/a): Béjar. Plano-Guía.

AYUNTAMIENTO DE BÉJAR (sin fecha/b): Béjar. Legado Salas.

AyUntamiento de BÉJar (sin fecha/c): Museo Municipal de Mateo Hernández.

AyUnTAMIENTO DE BÉJAR (sin fecha/d): Ruta de las Fábricas Textiles de Béjar.

Ayuntamiento DE BÉJAR (2004): Turismo. Disponible en Web: http://www.bejarturismo.com/turismo/ciudad.asp (ref. de 18.3.2010).

CAJaEspaña (2009): Datos económicos y Sociales. Béjar. Disponible en Web: http://internotes.cajaespana.es/pubweb/decyle.nsf/PorMunicipios/456F9485D576B4 1FC1256BB5003CC3C0/\$File/37046.PDF?OpenElement (ref. de 16.3.2010).

CÁMARA DE COMERCIO (2009): Entrevista con Esteban Rodríguez Izard, Secretario de la Cámara de Comercio (5.3.2009).

CAMERDATA, S. A. (2009): Fichero de empresas. Disponible en Web: http://www.camerdata.es/php/Productos/fichero_empresas.php (ref. de 9.6.2009).

DiPUTACIÓN DE SALAMANCA ( $\sin$ fecha): Paseos y Rutas de montaña por La Sierra de Béjar.

I-BÉJAR (2009): La ciudad de Béjar. Disponible en Web: http://www.i-bejar.com/

(ref. de 16.3.2010).

IMPUESTO SOBRE ACTIVIDADES ECONÓMICAS (IAE) (1999): Listado-IAE-1999-Béjar. Estadística facilitada por la Cámara de Comercio de Béjar.

IMPUESTO SOBRE ACTIVIDADES ECONÓMICAS (IAE) (2008): Listado-IAE-2008-Béjar. Estadística facilitada por la Cámara de Comercio de Béjar.

Instituto Nacional de EstadísticA (INE) (2008): Padrón Municipal. Salamanca: Población por municipios y sexo. Disponible en Web: http://www.ine.es/jaxi/tabla.do?path=/t20/ e260/a2008/10/\&file $=$ mun37.px\&type $=$ pcaxis $\& L=0$ (ref. de 18.3.2010).

Gestora de la Covatilla BéJar, S. A. (Gecobesa) (2009): Datos de esquiadores. Comparados por temporada.

Gestora de la Covatilla BÉJAR, S. A. (GeCobeSA) (2008): Junta General de Accionistas. 
Junta de CAstilla y León (JCyL) (2007): Guía de Servicios Turísticos Salamanca. JunTA DE CASTILlA Y LEÓN (JCyL) (2009): Plan General de Ordenación Urbana. Memoria Informativa.

LA CAIXA (2008a): Anuario Económico de España 2008. Base de datos municipal. Disponible en Web: http://www.anuarioeco.lacaixa.comunicacions.com/java/X (ref. de 17.3.2009).

LA CAIXA (2008b): Anuario Económico de España 2008. Metodología. Disponible en Web:

http://www.anuarioeco.lacaixa.comunicacions.com/java/X?cgi=caixa.glosarios.meto dologia.indic.pattern\&key=3 (ref. de 17.3.2009).

Museo Judío David Melul (2009): El Museo. Disponible en Web: http://www.museojudiobejar.com/ (ref. de 3.7.2009).

OFICINA DE TURISMO (2009a): Entrevistas con Carmen Sánchez, empleada en la Oficina de Turismo de Béjar, 5/03/2009

OfICINA DE TURISMO (2009b): Entrevistas con Carmen Sánchez, empleada en la Oficina de Turismo de Béjar, 27/03/2009

OfICINA DE TURISMO (2009c): Estadísticas Oficina de Turismo Enero-Diciembre 2008.

PARADORES DE TURISMO (2009): Paradores en proyecto. Disponible en Web: http://www.parador.es/es/portal.do;jsessionid=E24AC867D11FDF9DF231A768FF BAD950?IDM=135\&NM=3 (ref. de 18.3.2010).

SEGADE ILLÁN, A. (2005): Pasado, presente y futuro de La Covatilla.

SiSTEMA DE INFORMACIÓN TERRITORIAL DE LA JUNTA DE CASTILLA Y LEÓN (SITCyL) (2009): Visualizador de Mapas de la Junta de Castilla y León. Disponible en Web: http://www.sitcyl.jcyl.es/smap/index.jsp (ref. de 7.6.2009)

TRIBUNA DE SALAMANCA (2009): El museo textil de Béjar lleva un retraso de cuatro años para su inauguración. Disponible en Web: http://www.tribuna. net/ noticia/ 40009/PROVINCIA/ museo-textil-recibe-euros-finalizar-obras.html (referencia de 16.3.2010). 